\title{
El mundo de hoy visto desde Inglaterra
}

\author{
POR W. C. ATKINSON
}

Tenemos en Escocia un poeta, Robert Burns, del siglo XVIII, de fama mucho más que nacional como apóstol de la solidaridad humana. Suyo es un verso dejado caer al azar en un breve arranque lírico, que a fuerza de citarse ya pasa entre nosotros por apotegma. Vertido prosaicamente al castellano, reza así: "Quién nos capacitara para vernos a nosotros del modo que nos ven los demás!" No sonará a cosa muy profunda, pero profunda es en cuanto subraya lo complejo y difícil que es la comprensión entre los hombres, empezando por la comprensión del hombre de sí mismo. Si yo las más de las veces no me comprendo, si soy a la vez ser único yo múltiplec si soy uno vistordesde dentro y otro distinto desde fuera: ¿qué posibilidades tengo de acertar queriendo comprender a mi prójimo, y cuáles cuando se trata de juzgar a un desconocido, a un extranjero, siendo posible que me vaya la vida en no errar? En el fondo todos los hombres, todos los pueblos, anhelamos lo mismo la paz, la justicia, el mejoramiento progresivo de la vida para todos. ¿Porqué tanta dificultad para alcanzarlos? Tuvimos una guerra mundial, la guerra que había de acabar con todas las guerras para siempre, decíamos, justificándola en descargo de nuestra conciencia. $Y$ a los 21 años otra guerra mundial, y con el mismo enemigo. Es que tras una experiencia tan destructiva, lan desgarradora, y en tantos años, no habíamos aprendido nada del arte de la necesidad, de la convivencia. Y esta vez nos pusimos serios. La guerra tendrá sus causas, nos dijimos, independientemente de la voluntad de los hombres. Identifiquémoslas, formulémoslas, y luego podremos proceder a exorcisarlas. Guerra a las causas de la querra. Y proclamamos solem- 
nemente, mediada la guerra pasada, el dogma de las cuatro libertades, las cuatro garantías: Abajo el hambre, abajo el temor, arriba la libertad de expresiones, de conciencia. Y bajo el paraguas de las Naciones Unidas pudimos darnos organismos internacionales encargados de realizar tan hermoso programa. Esta vez sí habíamos conjurado el espectro de la guerra. Y a los 15 años, si hemos de creer a tanto estadista, tanto comentarista en los periódicos, nos hallamos temblando en el borde de otro cataclismo mil veces más amenazador, y el enemigo del mañana ya no será el mismo de ayer, sino el aliado, el que luchando valientemente a nuestro lado fraguó con nosotros la victoria, y esto, nos preguntamos, qué sentido tiene. Puede tenerlo, o el mundo va atrás y todos toleramos que no lleguemos a entendernos. Con el enemigo, se comprende. Pero si no hemos de llegar a entendernos ni aún con el amigo, hay motivos para desesperarse. $Y$ pensar que en aquel ya tan lejano siglo XIX, era punto de fe que el hombre, la sociedad, el mundo, progresaban de por sí, estando Dios en el Cielo y, gracias a los adelantos de la industria, aquí abajo. La ley del progreso ha sido la primera víctima del siglo XX y no parece sino que el hombre, los hombres y los pueblos, se comprenden los unos a los otros cada vez menos en lugar de cada vez más. Debería ser que la ciencia de que más precisamos hoy día, si no hemos de imitab a los bíblicos cerdos gádarenos y precipitarnos todos al suicidio, fuera no da física nuclear, ni, la economía política, ni el derecho internacional, sino sencillamente la psicología. El grito más apasionado que suena en nuestros oídos es el: ¿Pero cómo entendernos? ¿Porqué es que no nos entendemos? $Y$ aquí se me ocurre mentar esa observación tan leída y llevada de los estudiantes de lógica sobre lo imposible que es que dos personas resuelvan un argumento, siendo distintas sus premisas y distinta sus suposiciones. Hace años un ilustre sociólogo norteamericano escribió un libro que bien pudiera prescribirse como texto obligatorio en todas las facultades de todas las universidades. Me refiero a "La Tiranía de las Palabras", por Stewart Chase, en que demuestra sin dificultad que los más de los hombres la mayor parte del tiempo no tienen la menor idea de lo que están diciendo. Esas palabras llaves que rigen nuestro pensar y nuestro vivir, palabras como democracia, libertad, justicia, progreso ¿qué significan? Y no hablemos de los políticos, y menos en tiempo de elecciones, cuando lo más probable es que no significan nada. 
Pero si pidiendo definiciones hallamos, como seguramente hemos de hallar, que éstas rara vez o nunca coinciden entre sí, y aceptando que aun cuando coincidan son al fin $y$ al cabo palabras y que la piedra de toque ha de buscarse en como cada cual las lleve a la práctica, bajo condiciones quizá no previsibles, entra la tentación de preguntar si vale la pena tanto debate diplomático, sea en la cumbre, en las faldas, o al pie de la montaña. Tanto organismo internacional, tanto qué hacer y papeleo, que a lo mejor puede resultar contraproducente y a lo peor será pura fachada, engañando una vez más las esperanzas ya deseseperadas de la humanidad. Yo por mi parte, como académico y profesor de humanidades, abrigo la convicción de que de poco sirve abrigar la comprensión, enseñar el idioma de otro pueblo, su literatura, su historia, su modo de ser, si todo esto no va acompañado de la malicia de su modo de pensar, de sus procedimientos intelectuales conscientes e inconscientes, de su juego de convicciones, prejuicios, supersticiones y tantos elementos atávicos que pesan en esas premisas, esas suposiciones de que hace un momento hablábamos. Solo así, entablando una discusión con individuos de dicho pueblo, podremos penetrar el sentido de lo que dicen, intuir su reacción a lo que decimos nosotros, que para esto no sirve el diccionario. Pero hablamos de la importancia del punto de vista, $y$ es que pese a Copérnico seguimos todos con Tolomeo en nuestra cosmogonía política. El mundo gira alrededor de nosotros. Donde quiera que se "encuentrel radicado uno, álí sestá el centro de su universo. Se recordará la célebre ecuación aritmética: muerte de un millón de personas por el hambre, o la peste, en el Japón $=$ la muerte de cien mil en un terremoto en China = la muerte de cien mil en las inundaciones en la India - la muerte de mil en una revolución en Persia = la muerte de cien en un desastre de ferrocarril en Italia = la muerte de diez en un incendio en Francia $=$ a la posibilidad de que en Inglaterra muera yo. Aquí, en sintesis gráfica, la tragicomedia de las relaciones internacionales, y cuesta apreciar lo cómico, en medio de tanta tragedia, que encierra. Todos nos sentimos más o menos internacionalistas hoy día, viajamos gracias al avión como nunca viajaron nuestros padres, el mundo se achica ante nuestros ojos y tenemos la ilusión de hacer valer equivalencia por comprensibilidad. Pero algún aspecto del problema puede esquivar la tensión del estudioso cuando viaja, queriendo graduarse como ciudadano del mundo, 
y no hablo del curioso que tras una estadía de dos o tres semanas en un país dado preguntando, apuntando, fotografiando, cree haberlo visto y entendido todo, y vuelve a casa, sale con un libro más de esos titulados "¿Cómo vive la Unión Soviética?", o "El Enigma de la China Descifrado", o "La Verdad sobre el Africa del Sur". Tales reportajes honestos, ingenuos, forzosamente han de falsear el cuadro, si no fuera más que por la sugestión implícita de que no hay problema que resista un poco de buena fe y mucho de simplismo. Me refiero más bien a la pregunta que rara vez o nunca se nos ocurre hacer en un país extranjero: ¿y ustedes, señores, qué piensan de nosotros? ¿Cómo ven ustedes nuestro país, nuestra política, nuestra actuación en el escenario internacional? ¿Quién nos capacitará para vernos a nosotros del modo que nos ven los demás! Me permito invocar aquí una experiencia mía. Estando hace algunos años en Rusia y teniendo ocasión de hablar con toda clase de personas, así en la capital como en regiones muy distanciadas de ella, recordé repetidamente ¿pero porqué este país sigue alborotando a todo el mundo? ¿porqué este empeño en querellar con sus amigos y aliados de ayer? ¿porqué tanto preparativo militar, haciendo que todos vivamos en régimen de aprensión y tengamos que sacrificar a contingencias de una tercera guerra mundial, recursos y energías que aplicados constructivamente auspiciarían una nueva edad de oro y de abundancia para la humanidad entera? $Y_{i}$ me dijeron, aún no en tono de completa convicción y sinceridad, pero amigo ¿quién es el alborotador? No somos nosotros los responsables de esta mentalidad de crisis. Los amenazadores son otros, nosotros los amenazados. Y si no, explíquenos esa política de bases militares instaladas por cierta potencia occidental en tantos países de nuestro alrededor, todas con una sola mira, apuntando todas a la Unión Soviética. Ustedes en nuestras circunstancias no reaccionarían de otro modo. ¿No sería acto de traición al pueblo el que nuestro gobierno dejara de tomar todas las medidas recíprocas a su alcance? ¿Cómo creer palabras de paz si son belicosos los actos? Denota todo esto, claro está, una falta de confianza. Cada lado desconfía de la buena fe del otro. Toda medida defensiva de parte de uno pasa a ser ofensiva a otro del contrario, y el problema es como echar un puente a través del abismo, restablecer la confianza mutua, fraguar un idioma nuevo, psicológicamente hablando, en el que descontadas las reservas, las ambigüedades, las sospechas, se 
podrían discutir con el deseo, con la firme resolución de llegar a un acuerdo, y no como ahora de sacar partido, de desconcertar, de hacer propaganda. Y volviendo a mis charlas habidas en Moscú, diré que fue allí donde hice una observación de esas que por obvias suelen eludirnos. Es ésta: nosotros los ingleses hemos tenido muchas guerras en nuestra historia, en Francia, en Alemania, en España, en Rusia, en Africa, en el Asia, en América, en todas partes menos en Inglaterra, en casa. Desde hace más de 300 años, la guerra para Inglaterra ha significado montar un ejército y mandarlo allá fuera, a luchar contra el enemigo en su propio país, a devastar sus territorios a buen seguro de que la devastación, como la derrota, era destino reservado a otros. Por algo somos una isla. Y así hasta la primera guerra mundial; inclusive con la segunda llegó la gran Navidad. Ni Felipe II, ni Napoleón, ni Hitler siquiera consiguió desembarcar tropas en nuestras playas; pero gracias al avión sí pudo éste echarnos encima bombas y más bombas, y por fin vinieron los cohetes y buena parte de Londres y de otras ciudades más desapareció en las llamas. Por primera vez como pueblo supimos cómo es la guerra, y me parece que nuestra política internacional se resiente desde entonces acá de la experiencia. Ahora, Rusia sí sufrió la última guera, como la anterior, en su propia carne. El enemigo llegó a las puertas de Moscú, echó un cinturón de hierro alrededor de Leningrado, la segunda ciudad que durante unos 15 meses conoció un bombardeo constante, hizo tabla rasa de regiones enteras del país, destruyendo grandes potencialidades económicas e industriales. EE. UU., al contrario, ha gozado hasta el momento de esa feliz inmunidad que hasta hace 20 años habíamos creído nosotros también patrimonio nuestro, como por dispensación divina. Para ellos todavía la guerra es cosa de allá afuera, mientras sigue la vida de la nación detrás de sus fronteras y sus playas, como si tal cosa. Esto no durará si llega, lo que Dios no consienta, otra explosión. Porque ahora aviones y cohetes cruzan los océanos, como antaño el Canal de la Mancha. Pero mientras tanto me parece a mí que cuando un ruso dice que quiere la paz, que todo menos la vuelta a ello, lo dice con una fuerza de convicción aún mayor y más honda que la de otros no menos sinceros, pero que no han sufrido como él. Y si tuviéramos razón en esto, entonces tendríamos que admitir que por lo menos la posibilidad de que lo tortuosa que nos parece a menudo su política, la violencia de 
sus reacciones, el poco respeto por cuestiones de protocolo en su conducta diplomática, respondan no a designos maquiavélicos sino a su noción de cómo asegurar mejor la paz. En caso que no se pueda asegurar, mirar por la defensa de la patria. Y por más que nos ofendan, entre otras cosas, sus modales diplomáticos, hagámosle la justicia de reconocer que la Unión Soviética como país a la moderna data solamente de 1917, y que 43 años no son muchos para educar y pulir a todo un pueblo, a todo un puñado de pueblos, tan recién y tan violentamente salidos del feudalismo medieval. Yo, desde luego, no he venido aquí para erigirme en defensor del comunismo, de que, como de toda tiranía, abomino. Hablaba del problema de la comprensión entre las naciones y de cómo para comprender hay que empezar aprendiendo a situarnos en lugar de aquel a quien queremos comprender. La política del avestruz significa preferencia por la no comprensión, y este es un lujo cuyo precio dudo que ningún pueblo quiera ni pueda pagar hoy. Y, por fin, el tema: El mundo de hoy conforme se nos presenta en Inglaterra. El factor que quizá pese más que otro alguno, más aún que los cambios que se están produciendo, es el ritmo acelerado con que se producen. La velocidad es la nota caracterizada de nuestra época. Pocos detalles encuentro yo más impresionantes en la historia que esta simple observación. Que hasta hace siglo y medio, más ō menos, nadie había viajado jamás con velocidad superior a la del galope de un caballo, y ahora volamos a la del sonido, la friolerd de $\$, 000 \mathrm{kms}$. por hora y arriba. Pero tal movimiento vertiginoso a través del espacio es sólo símbolo de lo que está pasando en otras esferas. La misma naturaleza se está apresurando. Nos asegura la fisiología, que los niños crecen y alcanzan la pubertad meses antes con cada nueva generación. O sea cosa de cuatro años en un siglo. Y allí, de paso, problema de guerras. Una jaqueca para nuestros educadores, que quieren retenerles un año, dos años, más en la escuela. Pero fijémonos en los cambios políticos y sociales que se están operando por todos lados, nacidos tantos entre ellos -esto se reconoce en seguida- de las dos guerras mundiales. La guerra es el gran enemigo del status quo, y cuanto mayor en escala el conflicto, tanto más grave la amenaza que encierra a instituciones tenidas por sacrosantas. Quién nos dijera en 1914 que el colapso de Alemania cuatro años después, vendría acompañado del derrumbamiento de tronos por media Europa. Quién se atreviera 
a profetizar en 1939 que el triunfo de los aliados tras 6 años de lucha, habría de significar para ellos, los vencedores, y no para los vencidos, la desintegración de sus imperios, el fin próximo del colonialismo, no conforme a un programa de lenta capacitación, a través de décadas, de los pueblos coloniales, según el que recibirían éstos su independencia en cuanto demostrasen su total aptitud para tal responsabilidad y la existencia del cuerpo de administradores técnicos y educadores indispensables al debido funcionamiento del nuevo régimen. Se ha verificado más como resultado imprevisto de fuerzas desencadenadas al azar, fuerzas irracionales, incontrolables, que con el triunfo amenazan dar al traste con todos los valores recibidos. Tenemos ante los ojos en este momento el ejemplo elocuente de la República libre del Congo, nacida a la independencia hace unas semanas nada más y que ha tenido su bautismo de fuego en el momento mismo de nacer. Es el dilema tan conocido del casuista, fácil, relativamente fácil, escoger entre el bien y el mal. Es cuando hay que elegir entre un bien y otro bien que el juicio zozobra. Claro que la libertad es un bien. Para algunos el bien supremo. Pero la liberiad para qué, en pro de qué otro bien, a qué precio. El pueblo, ha dicho un sabio de nuestros días, tiene más necesidad de ser gobernado que de ser soberano. Y hay pueblos, y no sólo entre las razas más atrasadas del Africa tropical que parece tendrán que optar por mucho tiempo lodavía entre la jerarquía y la anarquía. Se opta naturaimente nol por anarquías sino por la libertad. Es cuando ésta degenera en anarquía que se impone lo otro, el gobierno autoritario, la dictadura militar en una forma o en otra. Luego vienen los gritos al cielo, de que la libertad ha sido traicionada. Pero la traición, verdad es ésta que muy pocos quieren reconocer, habrá venido de parte de los que no supieron conjugar libertad con responsabilidad. Y aquí un desengaño más entre tantos como nos ha brindado este mundo en que vivimos. Le ha costado un verdadero esfuerzo a Inglaterra, a través de los últimos 100 años, aceptar que la democracia, cuya innata superioridad a cualquier otro sistema político es para nosotros materia de dogma, esté sujeta a la misma relatividad de lo que fue despacio, que impera en todas las demás esferas. Pero hecho el esfuerzo, aceptado esto, hemos venido identificándonos con la convicción de que por lo menos todos los hombres, todos los pueblos, aspiran a la democracia, tienden hacia ella como meta predestinada 
de su larga y a veces tan penosa evolución social, día tras día, año tras año, El mundo por la fuerza se irá democratizando. $Y$ otra vez la ley del progreso, horrible pensamiento, amenaza fallarnos allí donde la democracia lucha de espaldas al muro por la vida. Más grave, mucho más grave aún; países hay en donde otro sistema funciona hasta mejor, produciendo resultados con los que no podría competir en igualdad de circunstancias el vuestro. Si Rusia, pongamos por ejemplo, se ha transformado en cosa de 40 años, saliendo de las tinieblas, de lo medieval, hasta poder parangonearse con los EE. UU. como una de las 2 grandes potencias del mundo, inútil eludirnos diciendo y repitiendo, como si a fuerza de repetición hubiera de convertirse en verdad, que el pueblo ruso gime bajo una tiranía que no podrá soportar mucho tiempo más y que el día menos pensado se sublevará, destruyendo hasta el último vestigio de tal régimen y convirtiéndose sin más en una democracia perfecta, tipo británico. Con que punto final a todos nuestros problemas. Las cosas no pasan así. La única respuesta eficaz que puede oponer un sistema político a otro que lo amenaza consiste, primero, en la demostración de que no hay nada de cuanto puede hacer éste que aquel no pueda hacer mejor, porque si sólo lo puede hacer igualmente bien, la elección seguirá siendo cosa de indiferencia y, segundo, en la creación de una sociedad tal, a al ningúna hombre libre, Suesto a escoger, le podría pasar por la mente optar por sacrificar la libertad en johl aras de otro Dios cualquiera. Y me parece que la batalla pudiera muy bien perderse si nos contentásemos con lo segundo, diciendo que los verdaderos valores de la democracia son más bien éticos, espirituales, intangibles, y que el hombre nació para la libertad, con derecho a la plena realización de su ser individual, ya que éste se ha respetado, por lo menos no se ha de contentar con menos; porque, aparte el creciente materialismo de este Siglo XX, entrará la tentación que para muchos pueblos será facilmente irresistible decir: Bien, perfectamente. Pero, mientras tanto, en lo que pasamos, los valores éticos serán lujos. Primero a mejorar nuestro nivel de vida, a levantarnos en el rango de las naciones, a conocer adelantos de la ciencia moderna de que blasonán otros. Luego lo otro. Y así el totalitarismo tendría ya el pie en el embrague. Veamos el caso de la China, aquella tremenda incógnita del horizonte actual. Hace un cuarto de siglo, nada más, los japoneses se habían atrevido a invadir y ocupar 
la Manchuria. Nada menos que el vasto territorio de un millón y cuarto de kms. ${ }^{2}$ China, también, a consecuencia de la guerra pasada, ha despertado de su letargo secular, ha reintegrado su territorio y se está modernizando a paso de gigante en todas las direcciones y ¡bajo qué auspicio! La llamada democracia de Chiang Kai Shek resultó ser un sueño de cachimba, como decimos. No, China está con los del bando opuesto, y el único consuelo que podemos sacar del caso es la esperanza que algunos abrigan de que dentro de algunas décadas, quizá muy pocas, China esté echando su sombra sobre la misma Unión Soviética e inquietando al gobierno de Moscú, a la vez que a los países democráticos. Mientras tanto, se sigue negando a la nueva China el derecho a sentarse entre las NN. UU., lo que no a todos les parecerá el medio más indicado para llegar a una posible base de convivencia con ella. No basta con vencer, decía en antaño, uno a otro. Hay que convencer. Hoy tenemos que rectificar. Abandonada igualmente toda posibilidad de conocer, hay que saber respetar, por honda que sea la divergencia, por repugnante que parezca la transacción. Como filosofía de la vida, respetar y dejar en paz, entre tantos rencores como infestan el escenario internacional en la actualidad. La disposición: "ha respetado al contrario", no puede decirse que descuelle. Por qué, me pregunto, entre dos gigantes como śon EE. UU. y la Unión-Soviética, de territo-

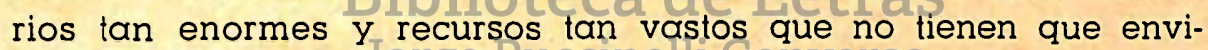
diarse nada el uno al otro, por qué este encons, esta rivalidad a muerte, en vez de seguir cada uno por su lado sin meterse para nada con el otro. También el odio teológico de tiempos pasados, convertido en odio político, con la misma fervorosa convicción de que el ferviente ortodoxo no ha de dejar peligrar su alma transigiendo con el hereje. Entra para mucho más, a mi ver, la lucha entre los dos por el alma de los pueblos todavía no comprometidos. Lucha agudizada siempre que asoma una nueva nación independiente. Es el ardor del misionario de antes, de propagar la fe y de ganar más adeptos. Es la oportunidad de asertar un golpe al rival, invadiendo su esfera de interés. Es a veces la necesidad de reforzar la propia fe, de poder aducir testimonio desde fuera para convencer a los tibios en casa. Lo acaecido en Hungría, en 1956, provocó horror y repugnancia entre los pueblos libres del occidente. Crimen contra la humanidad, contra la conciencia del mundo, se gritaba. Y con razón. Pero imposible con- 
vencer de esto a ningún ruso. ¿Y lo acaecido en Guatemala en 1954?, decían con completa convicción. EE. UU. dice no poder tolerar tan cerca de sus fronteras un régimen que por democrático forzosamente había de sernos hostil. Se ve cómo nos vemos cogidos en una situación en donde las acciones y reacciones, de racionales que debían ser, pasan a ser instintivas, medio automáticas. Mientras que de un solo país no identificado con él, un campo con el otro, la lucha parece que continuará, infiltración económica, intriga política, intromisión en la soberanía ajena, conforme califica el uno los actos del otro. Ayuda desinteresada, buena vecindad, comunión de intereses, de ideales, según califican los últimos. Y, cuando por fin el último pueblo verdaderamente libre haya sido ganado, entonces, a falta de un equilibrio tan exacto que no quepa pensar en socavarlo, seguirá la lucha con la mira puesta ya de cada lado en la total eliminación del contrario. Durante la guerra del 39 al 45 , es decir, durante los últimos años de ella y primeros de la llamada paz, cuando el tema de todos era cómo aprovechar la victoria para asegurar que eso nunca volviera a pasar, se oía hablar mucho de un solo mundo, de la esperanza de llegar a tal identidad de intereses entre todos los hombres, todos los pueblos, que permitiera suprimir la multiplicidad de gobiernos para llegar a un solo gobierno mundial, en cuya política, por no tener ya rival Bno podría Centraf ni rivalidad,Sni hostilidad contra nadie. He oídojhablar menos estos años pasgdos de un solo mundo, y me pregunto si como un ideal adolecía del mismo defecto de aquel otro de un solo idioma, gracias al que todos nos entenderíamos a todos y no habría más lugar, decían los muy ingenuos, para la incomprensión entre los pueblos. Porque, para los protagonistas del idioma único, pero siempre, cosa subentendida, que dicho idioma sería naturalmente el inglés, se había olvidado el dicho del cínico aquel para quien lo único que separa a los pueblos ingleses y norteamericanos es su común idioma. El sueño de un solo mundo suponía, sobraba decirlo, un mundo ganado en su totalidad para su democracia, y más habiendo tantos tipos de democracia, cuantos regímenes democráticos para un tipo fijo, prefijado de la misma. Curioso es notar ahora, cómo ahora que en nuestro mundo occidental se viene echando tierra muy discretamente sobre el concepto de un solo mundo, cómo lo están resucitando y adoptando como suyo los del otro bando, con el subentendido, otra vez, de que será un mundo ganado en su totalidad para el comu- 
nismo. El otro día nos aseguraba el mismo Kruschev, que él habría de vivir para verlo. Para el demócrata que llegara a compartir por inevitable esa convicción cabe duda de que la meta ésa de un solo mundo perdía en seguida todo su atractivo. El occidente no tiene más remedio ahora que luchar con toda su fuer. za para conservar la libertad. Veamos el dilema en que esto nos sitúa. El totalitario no tiene interés en consultar las preferencias de los demás, ya sea su propio pueblo, los vecinos, el mundo en general. No siendo la libertad santo de su devoción, para él la política consiste en amoldar a todos a su antojo, a sus finalidades, por la astucia si se prestan, por la amenaza y la fuerza, si no. El demócrata cree antes que nada en la libertad. Abajo la opresión. $Y$ libertad se define con relativa facilidad. Nunca más que relaliva, ya lo decíamos. En lo interno, libertad para hacer cuanto la ley permite, siendo la ley emanación de la voluntad de conciencia colectiva. Pero en las relaciones exteriores, queriendo promover la causa de la libertad en otro pueblo $X$, nos vemos en seguida asaltados de dificultades. Nos empeñamos en que dicho pueble goce de soberanía y tenga gobierno y régimen que mejor le cuadre. Perfectamente, en un principio. Pero pongamos el caso de que dicho pueblo, por falla de educación o práctica en el manejo de la responsabilidad, cae víctima luego, como dificilmente dejará de caer, de la democracia, de la explotación otra vez de la tiranía. ¿Qué habremos conseguido nosotros con esto? ¿Y qué

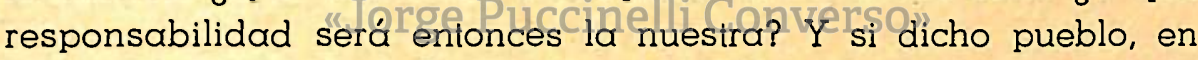
goce de su nueva soberanía, opta deliberadamente por aliarse con el enemigo, será de ver nuestro respeto de tal decisión en nombre de la libertad. Terrible impedimento es tener conciencia, principios en el trato con otros que no la admita. Quizá en el fondo libertad, es decir libertad ajena, signifique en nuestra mente libertad para hacer cuanto coincida con nuestros propios intereses, - por lo menos no esté en conflicto con ellos, esto, claro, tendría como corolario el cercenar nuestra propia libertad, reduciéndola a cuanto no pueda ofender los intereses ajenos. Y siendo imposible conseguir un mundo en que no surjan nunca intereses encontrados, es un círculo vicioso, un laberinto sin salida. Pero, por eso precisamente, y para eso fueron creados los organismos internacionales. Nadie ha de denegar la buena fe y el sentido de completa convicción, a la vez, que dieron urgencia, que precedieron a la creación de las NN. UU. en San Francisco en 1945. Y 
permítaseme destacar una nota del optimismo de aquellos días, nacida del hecho de que de las 51 naciones integrantes, más de la tercera parte correspondía a los pueblos de la América Latina, quienes hablando al unísono, como se suponía que por la fuerza hablarían, habían de ayudar grandemente para llevar el fiel de la balanza del lado de la justicia, la equidad, la democracia, siempre que surgieran los conflictos ideológicos. Yo estuve por casualidad en San Francisco en 1955, cuando se celebró allí una sesión especial de las NN. UU. en conmemoración de esos 10 años de múltiple actividad. Y me pareció notar que entre tanta realización sólida, tanto escollo esquivado, de que legítimamente se podía enorgullecer, se había aguado el vino de la fiesta como reconocimiento de que no basta todo el idealismo del mundo para cambiar la naturaleza básica del hombre. Echese fuera a ésta por la ventana, y volverán por la puerta de servicio las pasiones, los intereses, las ambiciones, las hostilidades. Eso es lo que tan a menudo se debate hoy día en las NN. UU. En donde, digamos de paso, con la creación casi a diario de tantas nuevas soberanías, con un total en la actualidad de unos 86 estados miembros, la voz de la América Latina pesa cada vez menos. Y no sirve decir que esto sí caracteriza la actuación de unos cuantos empeñados en obstaculizar todo cuanto no esté conforme con sus propios interesesi porque asi entramos cotradez en el terreno estéril de las definiciones y la total incompatibilidad de dos conceptos del porvenir de la humanidad. Y aun cuando así no fuera, los hechos son duros, y basta lo del Congo en estos mismos días para insinuar las sospechas de que las NN. UU. no sean sino la finísima fachada para mal disfrazar tanta desunión como reina adentro. Hemos de seguir haciendo lo posible y aun lo imposible, para mantener ese organismo con vida y eficacia, por reducida que sea ésta, como encarnación de nuestra última esperanza. Pero será un acto de fe que pide milagros quizá no realizables, en época tan cínica como la nuestra. El hecho bruto es éste. Que lejos de haberse exorcizado el temor de la faz de la tierra, gracias a un nuevo culto por parte de todos los pueblos, del arte de la convivencia, nos venimos acostumbrando por la fuerza a convivir precisamente con el temor. Sobresaltos, amenazas, sublevaciones, golpes de estado, son nuestro pan de todos los días. Y por encima, anublando el horizonte de un modo que explica por sí mismo la inquietud, la insstabilidad y los rastros 
de irresponsabilidad de la nueva generaclón, la sombra de la bomba atómica. Cuando Dios quiere perderle a uno, decían los romanos, primero le enloquece. Pero la desesperación es mala consejera, y el hombre no se resigna. Yo no me resigno a aceptar pasivamente tal suerte para la humanidad. Hay que sacar fuerzas de la misma desesperación. Buscar en este ambiente de temor que respiramos un tónico a la voluntad. Aceptar el desafío. Y bien podríamos empezar dudando que sea designio de Dios perder a la humanidad con tanto camino todavía por andar. Permítaseme traer a colación una vez más a Unamuno, quien en su libro, del sentido trágico de la vida en los hombres y en los pueblos, en el que buscan angustiosamente los cimientos de una religión personal suya capaz de dar sentido a la existencia y de satisfacer su anhelo de inmortalidad, saca tanto partido de aquel dicho de Schopenhauer, el pesimista, "bien puede ser que nos esté reservado la nada, pero por lo menos podremos portarnos de suerte que sea una injusticia". Nadie tiene derecho a pedirle a la colectividad, al gobiemo, a los gobiernos reunidos en Nueva York, Ginebra o donde sea, cualidades morales, normas éticas, un sentido de responsabilidad superiores a los que trae él al desempeño de su diario quehacer como ciudadano. Superior intelígencia sí. Aprecio mejor documentado de las cuestiones en debate. Pero esto es 10 de menos, dado que nuestro dilema deriva derecho, triste, de que la razón nos ha fallado como guía por el laberinto de la vida. La razón, así desnuda, se pone al servicio del mal como del bien. Para asegurar que sirve exclusivamente al bien hay que revestirla de otras dotes, de interés, de desinterés, de probidad. Son dotes de carácter moral. Estas dotes son las que más falta nos hacen hoy día que se echan de menos en todos los niveles de la sociedad y de allí su ausencia trasciende a los gobiernos, que al fin $y$ al cabo son hombres como los demás. En cuanto a los conflictos de intereses entre los gobiernos, sería absurdo pensar en que, al efectuarse un cambio de corazón en el individuo, de muchos individuos, se nabría de operar sin más la solución de las tensiones internacionales. Pero igualmente rechazable es que al individuo no le llegue cuota aparte de la responsabilidad. Mucha verdad encierra el dicho de que cada pueblo tiene el gobierno que merece. $Y$ en esto estriba, claro, la quinta esencia de nuestro credo democrático. El comunismo, para invocar de nuevo la pesadilla del mundo libre, aprovecha no me- 
nos nuestros errores y debilidades como sus propias fuerzas intrínsicas. Y para seguir siendo libres hemos de demostrar que merecemos serlo. Nunca en la historia del mundo han pesado tantas incógnitas sobre su porvenir. Por eso mismo hemos de precavernos así contra el demasiado pesimismo como contra el demasiado simplismo. Hace siglo y pico, Sarmiento en la Argentina planteó en términos nítidos que a su ver confrontaba su patria la civilización o la barbarie, y para nosotros hoy es muy fuerte la tentación de plantear el nuestro en términos idénticos. Pero de aquí a otros 100 años, de seguir existiendo nuestro mundo, es muy posible que la lucha ahora entablada, y que nos parece $\alpha$ veces lucha a muerte, les parezca a nuestros descendientes sólo un aspecto entre varios, y quizá no el decisivo, de la historia de mediados del siglo XX. Hasta hace poco, creíamos ver como una ley de la marcha de la civilización el tantas veces repetido trasplante de su centro de gravedad siempre hacia el occidente. De Grecia a Roma, de Roma a España, de Francia a Inglaterra, de allí a EE. UU., con la viva posibilidad de que con el tiempo la hegemonía pasara acá a la América Latina. Y ahora surge Rusia para disputarle a EE. UU. su primacía, y con la perspectiva ya mencionada de que la nueva China a su vez le disputa a Rusia la suya, la dirección de la marcha puede que sea otra vez de occidente a oriente. El problema de la coexistencia se solucionará. No sabemos cómo, si bien tengo para mí que para suavizar los roces políticos nada mejor tras el esfuerzo serio de comprender que empezamos por subrayar como medio este mismo fin, que multiplicar como ahora se están multiplicando los contactos culturales. Pero siendo la coexistencia el precio de la misma existencia, de un modo u otro se habrá de solucionar. Y aquí hemos de dejar hacer también a la evolución. Es fenómeno muy curioso en la política interna de Inglaterra notar cómo el abismo que un tiempo medió entre los dos partidos, conservador y laborista, ha venido cerrándose hasta el punto de que para grandes secciones de la de la clase obrera ya no vale la pena votar en contra de los conservadores para conseguir un cambio de régimen. Algo parecido sucede en EE. UU. con demócratas y republicanos. Y son quejas, las dos, bastantes huecas en verdad, pues ni son monárquicos los demócratas ni totalitarios los republicanos. Y el comunismo ha de evolucionar con el tiempo no menos que la democracia. No es decir que lleguen jamás a fundirse, pero del mismo modo 
que el secreto de la estabilidad en un país estable, estriba en el predominio de lo que une sobre lo que divide, la política más sana en época de tensión mundial como la que vivimos, consistirá no en extremar las posiciones, en exacerbar, en contestar amenaza con amenaza, sino en buscar lo que ambos contrincantes, o cuantos hayan, tengan en común, y fomentándolo, tratar de ir ensanchando esa tarea a expensas de la otra, la de las discordias.

Universidad de Glasgow.

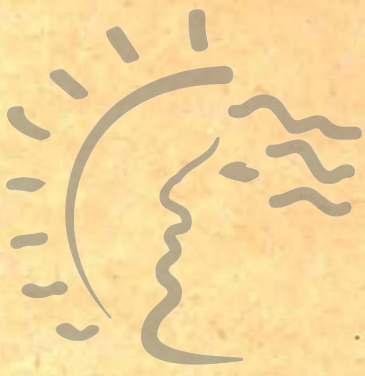

\section{Biblioteca de Letras}

